Article

\title{
Development, Physicochemical Characterization and In Vitro Anti-Inflammatory Activity of Solid Dispersions of $\alpha, \beta$ Amyrin Isolated from Protium Oilresin
}

\author{
Walter Ferreira da Silva Júnior ${ }^{1}$, Jonas Gabriel de Oliveira Pinheiro ${ }^{1}$, \\ Danielle Lima Bezerra de Menezes ${ }^{1}$, Natan Emanuell de Sobral e Silva ${ }^{1}$, \\ Patrícia Danielle Oliveira de Almeida ${ }^{2}$, Emerson Silva Lima ${ }^{2}$ (D), \\ Valdir Florêncio da Veiga Júnior ${ }^{3,4}$, Eduardo Pereira de Azevedo ${ }^{5}$ and \\ Ádley Antonini Neves de Lima ${ }^{1, *}$ \\ 1 Pharmacy Department, Health Sciences Center, Universidade Federal do Rio Grande do Norte (UFRN), \\ Natal 59012-570, Rio Grande do Norte (RN), Brazil; walterjuniornt@hotmail.com (W.F.d.S.J.); \\ jgopinheiro@gmail.com (J.G.d.O.P.); daniellelbmenezes@gmail.com (D.L.B.d.M.); \\ natan.farmacia@gmail.com (N.E.d.S.e.S.) \\ 2 Department of Pharmacy, Laboratory of Biological Activity, Federal University of Amazonas, Manaus \\ 69077-000, AM, Brazil; patt_danielle@hotmail.com (P.D.O.d.A.); eslima@ufam.edu.br (E.S.L.) \\ 3 Department of Chemistry, Institute of Exact Sciences, Federal University of Amazonas, Manaus 69077-000, \\ AM, Brazil; valdir.veiga@gmail.com \\ 4 Military Institute of Engineering, Rio de Janeiro 22290-270, RJ, Brazil \\ 5 Graduate Program in Biotechnology, Laureate International Universities-UnP, Natal 59056-000, RN, Brazil; \\ azevedoep@hotmail.com \\ * Correspondence: adleyantonini@yahoo.com.br; Tel.: +55-84-99928-8864
}

Received: 4 August 2017; Accepted: 6 September 2017; Published: 9 September 2017

\begin{abstract}
Amyrin (ABAM) is a natural mixture of pentacyclic triterpenes that has shown a variety of pharmacological properties, including anti-inflammatory effect. ABAM is isolated from Burseraceae oilresins, especially from the Protium species, which is commonly found in the Brazilian Amazon. This work aimed to develop solid dispersions (SD) of ABAM with the following hydrophilic polymers: polyvinylpyrrolidone (PVP-K30), polyethylene glycol (PEG-6000) and hydroxypropylmethylcellulose (HPMC). The SDs were prepared by physical mixture (PM), kneading (KND) and rotary evaporation (RE) methods. In order to verify any interaction between ABAM and the hydrophilic polymers, physicochemical characterization was performed by Fourier transform infrared (FTIR), scanning electron microscopy (SEM), powder X-ray diffraction (XRD), thermogravimetry (TG) and differential scanning calorimetry (DSC) analysis. Furthermore, an in vitro anti-inflammatory assay was performed with ABAM alone and as SDs with the hydrophilic polymers. The results from the characterization analysis show that the SDs were able to induce changes in the physicochemical properties of ABAM, which suggests interaction with the polymer matrix. In vitro anti-inflammatory assay showed that the SDs improved the anti-inflammatory activity of ABAM and showed no cytotoxicity. In conclusion, this study showed the potential use of SDs as an efficient tool for improving the stability and anti-inflammatory activity of ABAM without cytotoxicity.
\end{abstract}

Keywords: $\alpha, \beta$ amyrin; pentacyclic triterpenes; solid dispersions; hydrophilic polymers; anti-inflammatory activity 


\section{Introduction}

The Burseraceae family has 18 genres and around 700 species that are distributed throughout three different tribes: Canarieae, Protieae and Bursereae. This family is located at places with low altitude and without intense cold, including tropical and drought forests as well as deserts [1]. Protium heptaphyllum, a common tree found in Brazilian Amazon, is one of the most widely studied species. It is popularly known as almecegueira, breu-branco verdadeiro, almecegueira-cheirosa, almecegueira-de-cheiro and almecegueiro-bravo [2].

An oilresin is either produced when the trunk of Protium heptaphyllum is injured or naturally exuded. It is generally used in popular medicine for its anti-inflammatory, analgesic, expectorant and wound healing properties [3]. Several studies have shown the presence of secondary metabolites in Protium heptaphyllum, especially triterpenes such as $\alpha, \beta$ amyrin (ABAM) [4].

Terpenes are biologically versatile molecules consisting of subunits of isoprene, which can be classified as monoterpenes (C10), sesquiterpenes (C15), diterpenes (C20), triterpenes (C30) and tetraterpenes (C40), commonly observed as complex mixtures. $\alpha$ and $\beta$ amyrin are two pentacyclic triterpenes that belong to the ursano ( $\alpha$ amyrin) and oleano ( $\beta$ amyrin) series [5,6]. Several pharmacological studies have shown the biological activities of ABAM, such as anti-inflammatory [7], antinoceptive, hepatoprotective [8], antipruritic [9] and gastroprotective [10] activities, which make it a promising candidate for a new drug.

Despite the potential medical benefits of ABAM, its low aqueous solubility limits its use as a drug. Thus, strategies such as salt formation [11], particle size reduction [12-14], formation of solid dispersion [15] and complexation with cyclodextrins [16] have been used to enhance the solubility of ABAM and increase its dissolution rate.

The use of hydrophilic polymeric matrices for the development of solid dispersions (SD) with new drug candidates has been shown to be an effective alternative to enhance the drug's pharmacokinetic properties. SD is a well stablished technique that has been widely used due to its simple and straightforward approach [17]. However, miscibility between drug and hydrophilic polymer is an important factor for both solubility enhancement and physical stability of the obtained SD [18].

Trial and error experiments govern the process of choosing the right polymeric excipients for pharmaceutical formulations, where no systematic method is available to select the most suitable functional polymer for a particular system. However, studies have shown the importance of evaluating the interaction of different drugs with individual polymers and the effect of drug-polymer ratio on the drug's stability and dissolution rate [19-22].

Thus, this current study aimed to develop SDs of ABAM with hydrophilic polymers (PVP-K30, PEG-6000 and HPMC) with the purpose of improving the solubility and stability of ABAM, as well as to enhance its anti-inflammatory activity. In order to investigate interactions between each hydrophilic polymer and ABAM within the solid dispersions, physicochemical characterization was performed by FTIR, SEM, XRD, TGA and DSC. In addition, an in vitro study was performed with ABAM alone and as SDs using an inflammation model based on the inhibition of LPS-stimulated J774 macrophages. Finally, a cytotoxicity assay was undertaken to determine the viability of cell growth.

\section{Results and Discussion}

\subsection{Physicochemical Characterization}

\subsubsection{Fourier Transform Infrared-FTIR}

According to the FTIR spectrum for ABAM (Figure 1A), the high intensity band found at approximately $2800 \mathrm{~cm}^{-1}$ is associated with axial deformation of the $\mathrm{C}-\mathrm{H}$ bonds in aliphatic chains. In fact, most of the ABAM structure consists of aliphatic cycloalkane chains. In addition, the band at the $3250-3400 \mathrm{~cm}^{-1}$ region is attributed to a hydroxyl group $(\mathrm{O}-\mathrm{H})$ linked to an aliphatic carbon chain, and the one at the $1031-1100 \mathrm{~cm}^{-1}$ region is due to the vibration of the $\mathrm{C}-\mathrm{O}$ bond. Finally, the band at 
the $1400-1350 \mathrm{~cm}^{-1}$ region is characteristic of angular deformation of doublet germinal dimethyl and methyl groups [23-25].

The FTIR spectrum for HPMC (Figure 1B) shows a high intensity band in the $3443 \mathrm{~cm}^{-1}$ region related to the stretching of the O-H bond, as well as at $2935 \mathrm{~cm}^{-1}$ corresponding to the stretching of the $\mathrm{C}-\mathrm{H}$ bond and at $1651 \mathrm{~cm}^{-1}$ and $1069 \mathrm{~cm}^{-1}$, corresponding to $\mathrm{C}=\mathrm{O}$ bond of glucose units and C-O-C, respectively. On the other hand, the FTIR spectrum of PEG 6000 (Figure 1C) shows bands at $2980 \mathrm{~cm}^{-1}$, which is due to the stretching of the $\mathrm{C}-\mathrm{H}$ bond and another one at $1110 \mathrm{~cm}^{-1}$ related to stretching of an ester bond. The spectrum of PVP K-30 (Figure 1D) reveals strong bands around $2955 \mathrm{~cm}^{-1}$ corresponding to the stretching of the $\mathrm{C}-\mathrm{H}$ bond, as well as at $1647 \mathrm{~cm}^{-1}$, which is attributed to the stretching of the C-O bond. A wide band is observed at approximately $3425 \mathrm{~cm}^{-1}$, which is attributed to the presence of water molecules as further confirmed by thermogravimetric analysis.

When comparing the spectrum of the physical mixture of ABAM and HPMC with those of each individual compound, a spectral overlapping is observed as a result of the sum of each isolated compound. On the other hand, significant changes can be observed in the spectra of the SDs obtained through KND and RE, especially in the fingerprint region around $1500 \mathrm{~cm}^{-1}$. In addition, an enlargement of the band around $3250-3400 \mathrm{~cm}^{-1}$ and a decrease in the intensity of the one at $2800 \mathrm{~cm}^{-1}$ can be observed in the SD obtained by RE.

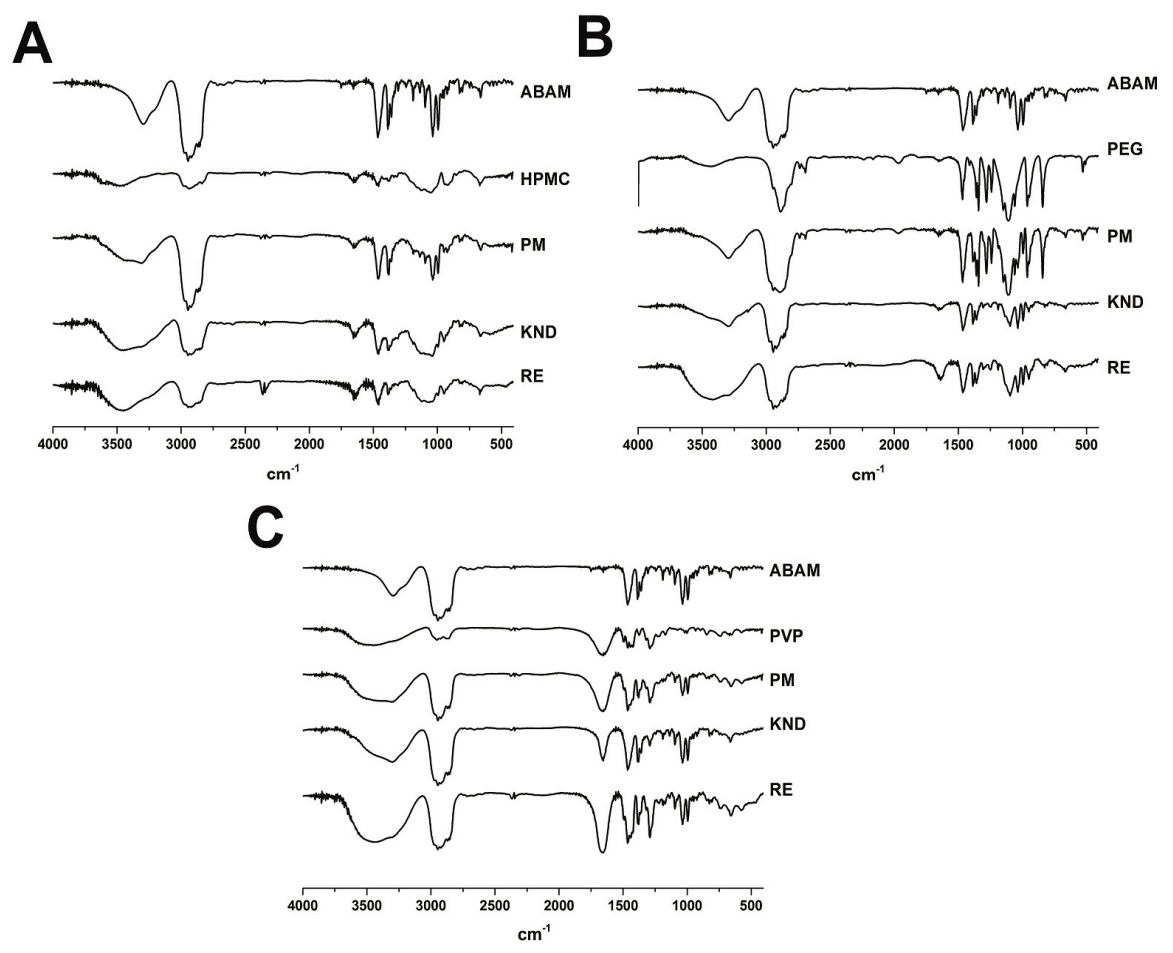

Figure 1. FTIR spectra of ABAM, HPMC and solid dispersions of ABAM with HPMC (A) FTIR spectra of ABAM, PEG-6000 and solid dispersions of ABAM with HPMC (B) and FTIR spectra of ABAM, PVP K-30 and solid dispersions of ABAM with PVP-K30 (C).

The FTIR spectra of the PM of ABAM and PEG 6000 as well as its solid dispersions obtained by KND and RE show a decrease in the band in the $3250-3400 \mathrm{~cm}^{-1}$ region in comparison with that of the ABAM itself, although the decrease in this band was much more intense in the solid dispersion when compared to that of the PM. In addition, the intensity of the band around $2800 \mathrm{~cm}^{-1}$ (characteristic of $\mathrm{C}-\mathrm{H}$ bonds in aliphatic chains of ABAM) decreased in the SD prepared by KND and RE. However, no significant changes were observed between the FTIR spectrum of ABAM with that of its PM. A significant decrease in the intensity of the bands in the $1600-750 \mathrm{~cm}^{-1}$ region was also observed in 
the SD of ABAM with PEG 6000 prepared by KND and RE, whereas an increase in these bands was observed with the PM of ABAM and PEG 6000. Therefore, the most significant changes in the intensity of the bands around the fingerprint region of ABAM occurred with the SD prepared with PEG 6000 by $\mathrm{RE}$, which seems to indicate a greater interaction between ABAM and PEG 6000 in the solid dispersion prepared by this method.

The FTIR spectra of the physical mixtures of ABAM and PVP K-30 as well as their solid dispersions obtained by KND and RE were also compared with that of ABAM alone. A decrease in the intensity and an enlargement of the band in the region around $3250-3400 \mathrm{~cm}^{-1}$ can be observed. No significant changes were observed around $2800 \mathrm{~cm}^{-1}$ in the PM and SD of ABAM and PVP K-30. A new low intensity band appears at the $1600-750 \mathrm{~cm}^{-1}$ region in the PM and SDs, which might indicate some interaction between ABAM and PVP K-30. However, significant changes occurred in the bands at the fingerprint region of ABAM when prepared as solid dispersion with PVP K-30 by RE, which seems to indicate that this method provide greater interaction between ABAM and PVP K30.

\subsubsection{Scanning Electronic Microcopy}

The SEM micrographs of the hydrophilic polymers, ABAM, PM and SDs are shown in Figure 2. The ABAM particles presented itself as geometrically irregular orthorhombic crystals. PVP K-30 (Figure 2D) showed spherical and amorphous particles, whereas PEG-6000 (Figure 2C) and HPMC (Figure 2B) particles are more porous and irregular.

The SEM pictures of the PMs of ABAM and HPMC (Figure 2E), PEG 6000 (Figure 2F), and PVP K-30 (Figure 2G) clearly show morphological heterogeneities, which seems to indicate that ABAM is simply dispersed on the polymer surface. On the other hand, the SDs prepared by KND and RE show an overall change in the morphology, evidenced by the absence of ABAM's crystals (Figure 2H-M). The morphology of each individual component cannot be distinguished in the SDs, which might indicate that $\mathrm{ABAM}$ is molecularly dispersed within the polymer matrix. It is worth mentioning that a polymeric film was formed on the SDs of ABAM with HPMC prepared by KND (Figure $2 \mathrm{H}$ ) and RE (Figure 2K), which must be due to the ability of cellulose derivatives to form films after the solvent is evaporated. This phenomenon was not observed with the other polymers.

\subsubsection{Powder X-ray Diffraction}

The X-ray diffractograms of ABAM and each polymer as well as their corresponding PMs and SDs are presented in Figure 3. According to the concept of crystalline powders, these solids are characterized by three-dimensional structures that are able to diffract $X$-rays and exhibit a well-defined melting point [26]. The X-ray diffractograms of PVP and HPMC display a halo pattern, which is characteristic of amorphous powders [27], whereas PEG 6000 shows a diffraction pattern at $18.9^{\circ}$ and $23^{\circ}$. On the other hand, intense crystalline diffraction peaks can be observed at $4^{\circ}$ and $13^{\circ}$ in the diffractogram of ABAM alone. In addition, other crystalline reflections of lower intensities $\left(6^{\circ}, 10^{\circ}\right.$, $11^{\circ}, 14^{\circ}$ and $16^{\circ}$ ) are present in the ABAM diffractogram.

The crystallinity of ABAM particles might explain its poor aqueous solubility. Therefore, the amorphization that occurs when drugs are prepared as solid dispersions usually leads to a significant increase in the drug's dissolution rate [28,29]. Although the crystalline reflections of ABAM were slightly reduced in the PM with HPMC, no change was observed with the PMs obtained with PVP K-30 and PEG 6000, which indicate that the PMs were not able to significantly reduce the crystallinity of ABAM. The SDs of ABAM obtained by KND with PEG 6000 (Figure 3B) and PVP K-30 (Figure 3C) slightly changed the crystallinity of ABAM, which is similar to what occurred with the PMs. The SD of ABAM with HPMC prepared by KND (Figure 3A) showed a greater reduction in ABAM's crystalline reflections. The XRD patterns of the SDs obtained by RE show that this method is more effective in reducing the crystallinity of ABAM. On the other hand, SDs prepared with both HPMC and PVP obtained by RE significantly reduced ABAM's crystallinity as most of its crystalline reflections almost disappeared. The SD of ABAM with PEG 6000 prepared by RE reduced the crystallinity of ABAM to a 
greater extent when compared to PM and KND methods; however, much of the crystalline reflection of ABAM was retained.

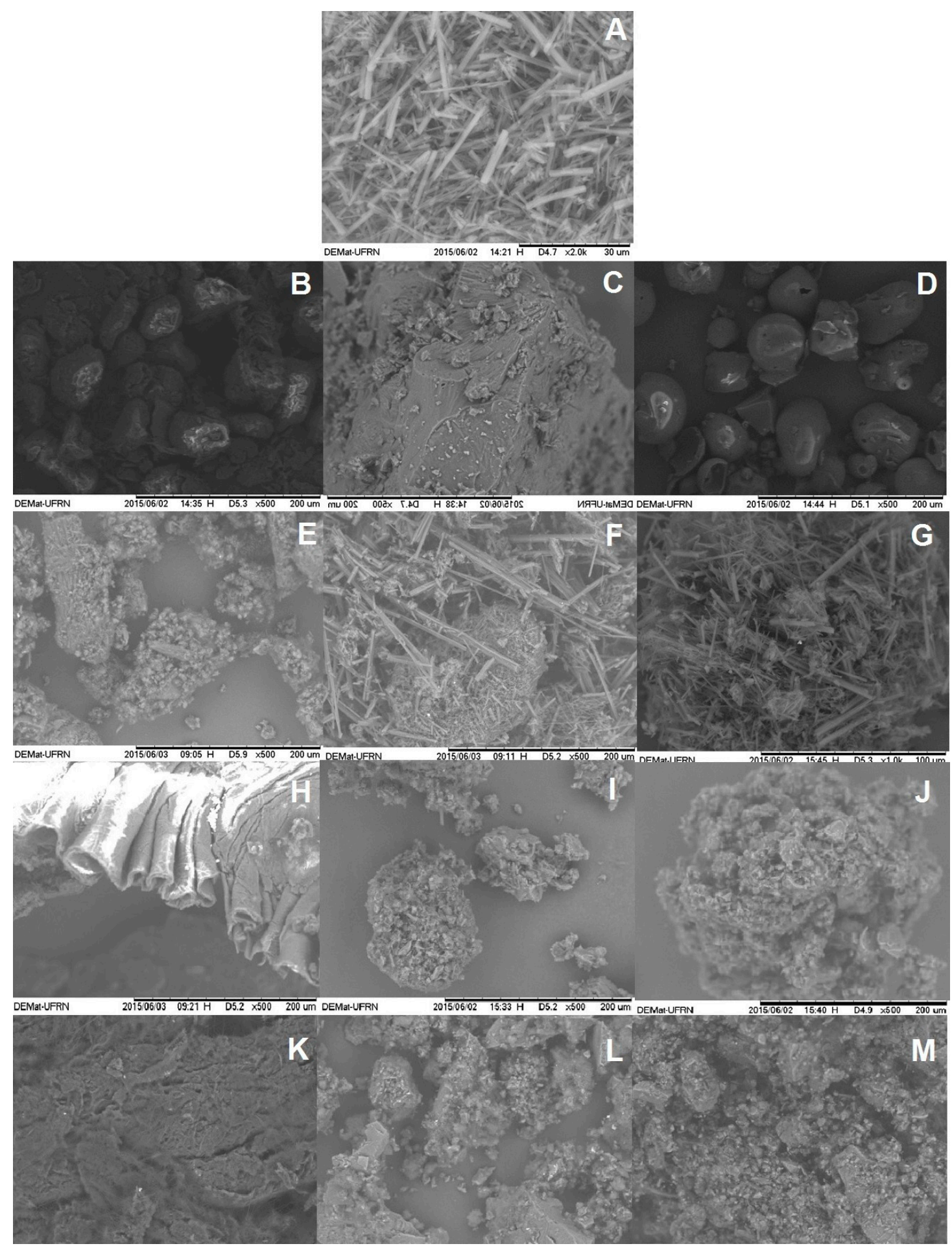

Figure 2. SEM micrographs of ABAM (A), HPMC (B) PEG-6000 (C), PVP K-30 (D), PMs of ABAM and HPMC (E), ABAM and PEG 6000 (F) and ABAM and PVP K-30 (G). SDs prepared by KND of ABAM and HPMC (H), ABAM and PEG 6000 (I) and ABAM and PVP K-30 (J). SDs prepared by RE of ABAM and HPMC (K), ABAM and PEG 6000 (L) and ABAM and PVP K-30 (M). 


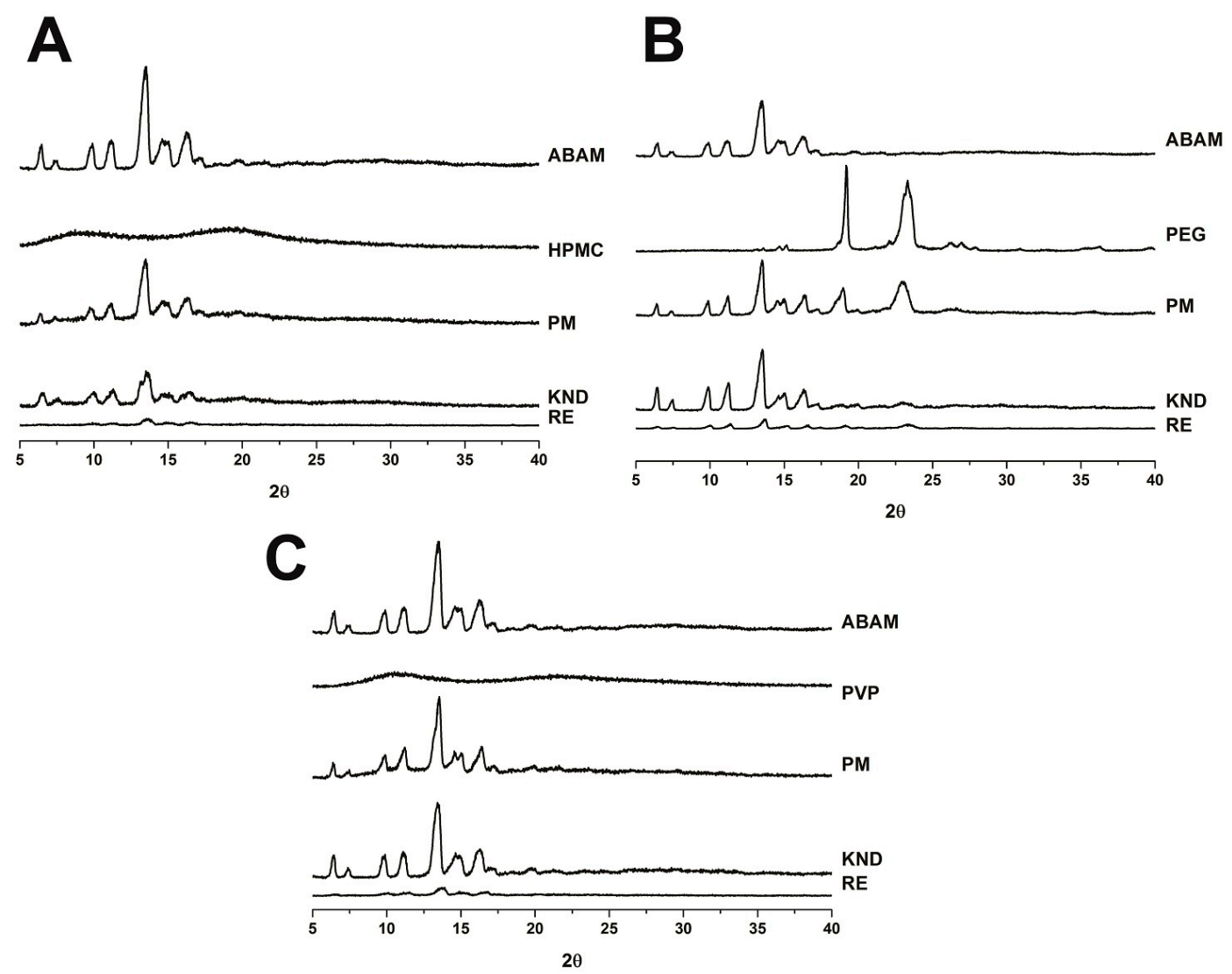

Figure 3. X-ray diffractograms of solid dispersions of ABAM with HPMC (A) PEG 6000 (B) and PVP $\mathrm{K}-30(\mathbf{C})$.

\subsubsection{Thermogravimetric Analysis}

The thermal behavior of pharmaceuticals is crucial as it can provide important information regarding formulation stability. In addition, it may reveal incompatibilities between the drug and excipients [30]. The TG curve for ABAM shows only one well-defined stage of mass loss, which is related to its volatilization (Figure 4$)$. The percentage of mass loss $(\Delta \mathrm{m} \%)$ was around $99.5 \%$, where the initial and final temperatures of the mass loss were 232 and $347^{\circ} \mathrm{C}$, respectively. TG results for HPMC showed high thermal stability, whose mass loss occurred in a single step, starting at $335{ }^{\circ} \mathrm{C}$ and ending at $425{ }^{\circ} \mathrm{C}$ with approximately $93 \%$ of $\Delta \mathrm{m} \%$ (Figure 4A). PEG 6000 also presented a single step for mass loss (93.5\%) within the temperature range of $338-448{ }^{\circ} \mathrm{C}$ (Figure $4 \mathrm{~B}$ ). TG curve for PVP K-30 shows a mass loss related to its water content $(\Delta \mathrm{m}=13 \%)$, which occurred between 42 and $102{ }^{\circ} \mathrm{C}$. Further, a main decomposition step was observed between 400 and $488^{\circ} \mathrm{C}(68 \%$ of mass loss), followed by carbonization (Figure 4C).

In this study, all dispersed systems showed an increase in the thermal stability when compared to that of ABAM alone, suggesting that the hydrophilic polymers were able to protect this drug. For ABAM and HPMC, no difference was observed among the TG curves for PM, KND and RE. On the other hand, ABAM and PEG 6000 (Figure 4B) prepared by PM and RE methods presented higher thermal stability in comparison with that obtained by KND. Figure 4B shows that SD of ABAM and PEG 6000 showed better thermal stability than that prepared by PM. The TG curves for PM and SD prepared with PVP K-30 (Figure 4C) showed an initial mass loss due to elimination of water, which is in agreement with the TG curve for PVP K-30 alone. Moreover, samples prepared by PM and RE showed better results than that prepared by KND, where the SD prepared by RE showed the best result regarding the enhancement of the thermal stability of ABAM. 


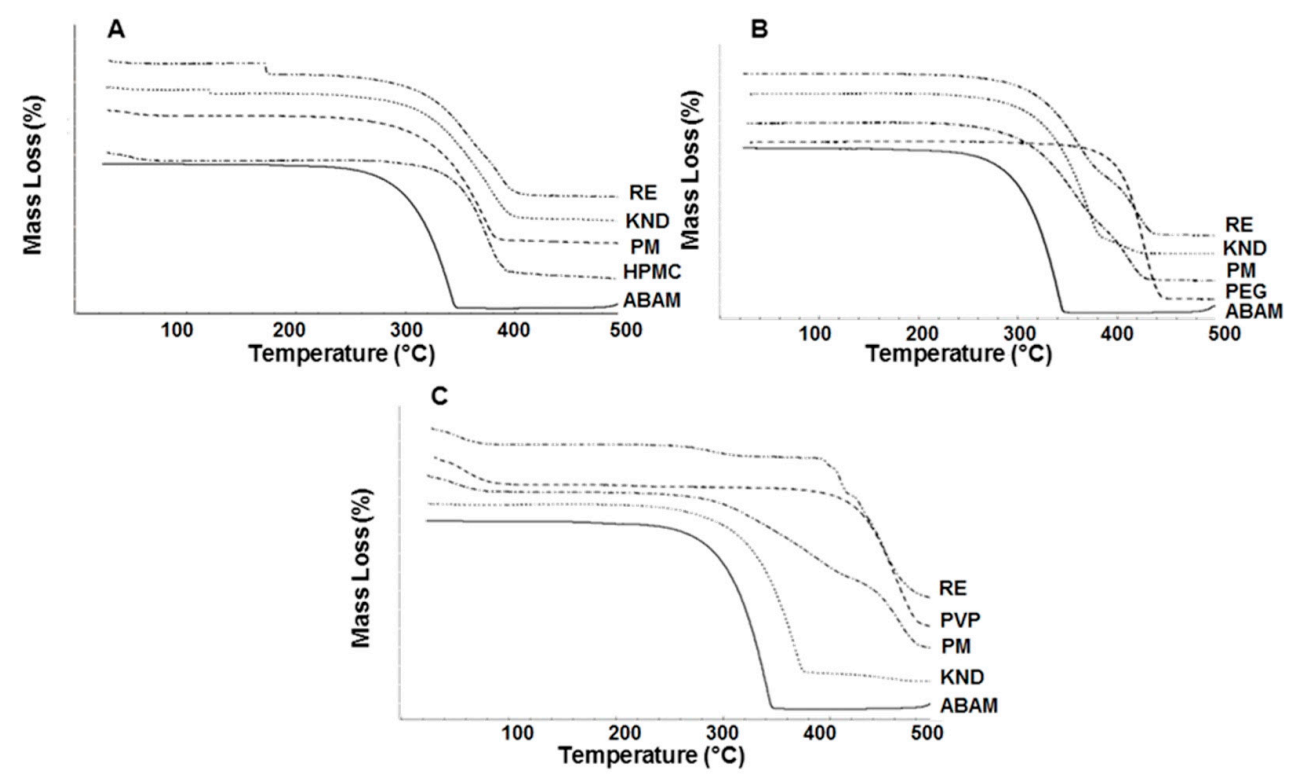

Figure 4. (A) TG curves for ABAM and HPMC alone, as well as PM and SDs prepared by KND and RE; (B) TG curves for ABAM and PEG 6000 alone, as well as PM and SDs prepared by KND and RE;

(C) TG curves for ABAM and PVP K-30 alone, as well as PM and SDs prepared by KND and RE.

\subsubsection{Differential Scanning Calorimetry}

The DSC curves for ABAM (Figure 5) show two endothermic events between 158 and $185^{\circ} \mathrm{C}$, which seem to be related to the melting of the two ABAM isomers. These two events are followed by a third endothermic event, which coincides with the weight loss due to volatilization observed in the TG analysis (Figure 4). Although PVP K-30 has several endothermic events due to the loss of water in the range of $50-120^{\circ} \mathrm{C}$ (weight loss of $12.26 \%$ ), no endothermic event is expected due to its amorphous characteristic. However, a melting endothermic peak around $65^{\circ} \mathrm{C}$ is observed, which is probably due to loss of water. A similar profile was found with HPMC, which is another amorphous polymer, where an initial endothermic event related to water loss was also observed.

The DSC curve for PM of ABAM with HPMC shows a depression of the ABAM's melting point, which seems be related to a partial solubilization of this drug in the polymer matrix, even though the melting event confirms the crystalline nature of ABAM in the PM. On the other hand, the SDs obtained with HPMC (KND and RE) showed an almost total suppression of the melting point of ABAM, suggesting the amorphization of the latter as well as a molecular interaction with HPMC. Regarding the systems obtained with PEG 6000, the DSC curves for the samples obtained by PM and KND show that the endothermic peaks related to ABAM's melting still persist, confirming its crystalline character is these systems. However, the curve for the SD obtained by RE shows the complete disappearance of this endothermic event, which can be attributed to a molecular interaction between ABAM and PEG 6000, resulting in its solubilization in the PEG 6000 matrix before it reached its melting temperature. Similar finding was observed by Kumar and Mishra [31]. Samples prepared with PVP-K30 by PM and KND show DSC curves with decreased melting points for ABAM, whereas the SD prepared by RE shows no endothermic event, indicating the formation of a solid dispersion, where the drug seems to be dispersed within the polymer matrix in the amorphous state.

This phenomenon is very common when PVP is used as a polymer matrix in solid dispersions. It has been attributed to the inhibition of drug's crystallization due to either a chemical interaction (such as hydrogen bonding between the drug molecule and the polymer) or a solvent evaporation process. In solvent evaporation methods, the slow removal of the solvent makes the system more viscous, reducing the mobility of the drug. Once the solvent is completely evaporated, the drug is 
frozen in the polymer matrix without forming a crystal lattice (a characteristic of the randomly ordered amorphous state) [32].

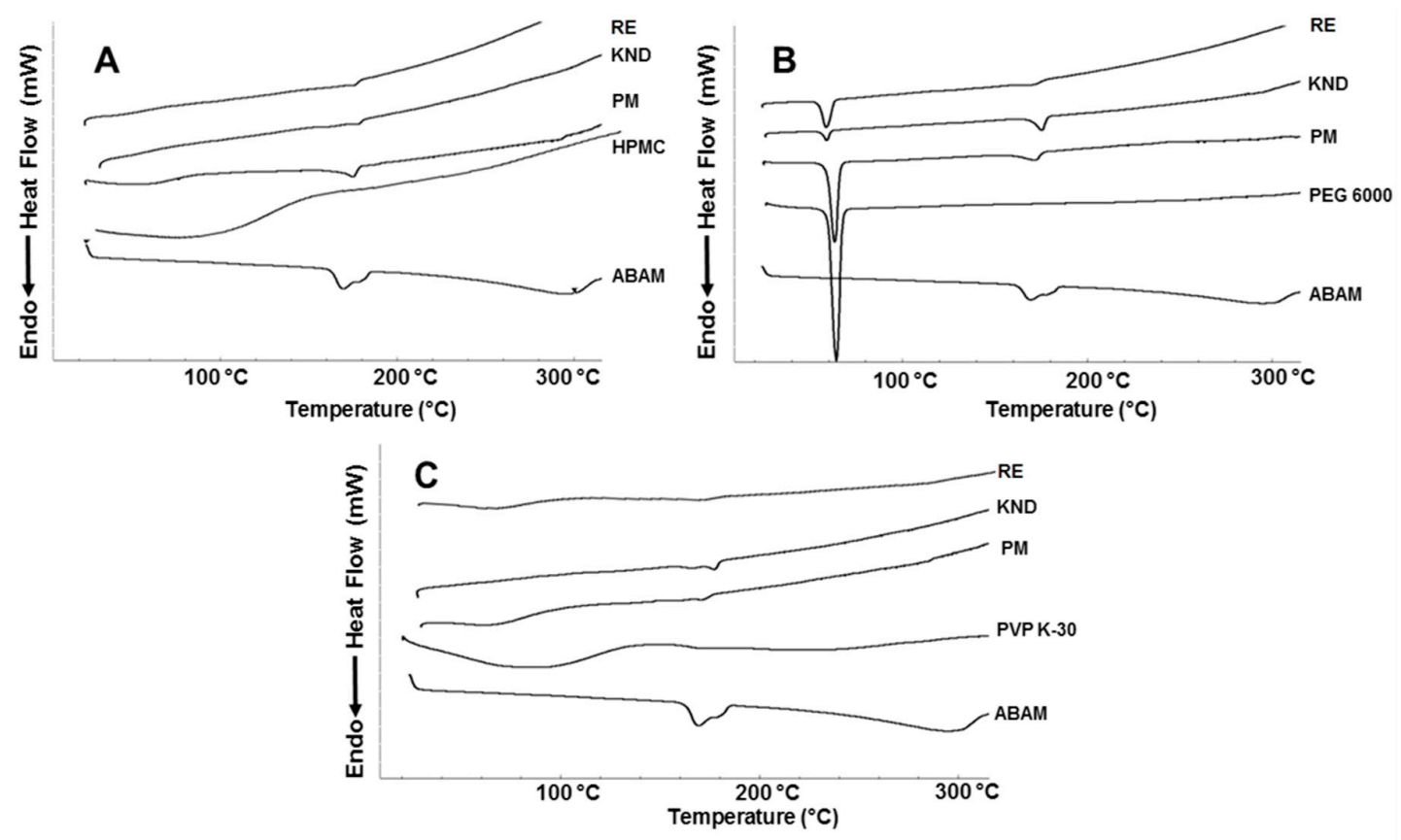

Figure 5. (A) DSC curves for ABAM and HPMC alone, as well as PM and SDs prepared by KND and RE; (B) DSC curves for ABAM and PEG 6000 alone, as well as PM and SDs prepared by KND and RE;

(C) DSC curves for ABAM and PVP K-30 alone, as well as PM and SDs prepared by KND and RE.

\subsection{In Vitro Anti-Inflammatory Activity}

\subsubsection{Quantification of Nitric Oxide in LPS-Stimulated Macrophages}

Inflammation is one of the most important processes involved in the organism's defense system, but it often progresses to chronic diseases that require pharmacological treatment. Natural products, including plant metabolites, represent great potential for the development of modern therapeutic drugs with anti-inflammatory activity [7]. Nitric oxide (NO.) is one of the major mediators of inflammation and its overproduction is associated with serious diseases such as septic shock, arthritis, stroke, chronic inflammatory conditions and autoimmune diseases. Thus, determination of the rate of NO- production in LPS-stimulated models has been widely used as an important parameter in the search for new anti-inflammatory drugs [33].

The anti-inflammatory effects of ABAM have been largely described in different experimental models through the inhibition of release of the pro-inflammatory cytokines interleukin- $1 \beta$, interleukin-6, tumor necrosis factor $\alpha$, as well as the enzyme myeloperoxidase [6,9]. In this study, the effect of ABAM and its solid dispersions on the production of NO- in LPS-stimulated macrophages was investigated. The anti-inflammatory potential of ABAM and its SDs is shown in Figure 6 and in Table 1. ABAM alone and as SDs (concentration of $20 \mu \mathrm{g} / \mathrm{mL}$ ) inhibited the production of NO. after $24 \mathrm{~h}$ when compared to the LPS group. The SDs decreased the production of NO- to a greater extent when compared to those of the control and ABAM alone $(p<0.05)$, indicating an improvement in the anti-inflammatory activity of ABAM when administered as SDs. It seems reasonable to assume that the solid dispersion obtained using those hydrophilic polymers is effective in enhancing the solubility of ABAM, thereby making it more bioavailable, which probably resulted in an enhanced anti-inflammatory activity. 


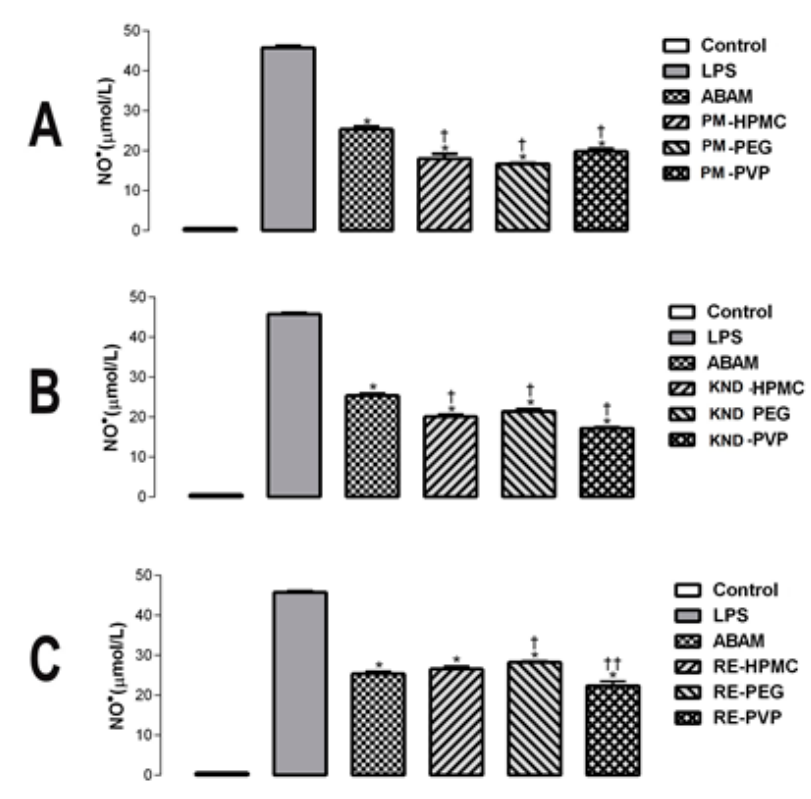

Figure 6. Effect of ABAM (alone and as a solid dispersion with hydrophilic polymers) on the production NO. in J774 macrophages stimulated by LPS. (A) NO production in the presence of ABAM alone and as PMs compared to that of the LPS group (B) NO- production in the presence of ABAM alone and as a SD prepared by KND compared to that of the LPS group (C) NO. production in the presence of ABAM alone and as SD prepared by RE compared to that of the LPS group. Values expressed as mean \pm SD (eror bar) with $n=5$. ${ }^{*} p<0.0001$, when compared to LSP group; $\uparrow p<0.05$ or $+\dagger p<0.01$ when compared to ABAM and its SDs. Statistical analysis performed by one-way ANOVA followed by Newman-Keuls test.

Table 1. Inhibition of LPS-induced NO production from J774 macrophages by ABAM alone and as SDs.

\begin{tabular}{cccc}
\hline Sample & Concentration $(\boldsymbol{\mu g} / \mathbf{m L})$ & NO $^{-}$Concentration & \% Inhibition \\
\hline LPS & 1 & $45.75 \pm 0.855$ & 0 \\
ABAM & 20 & $25.37 \pm 1.237$ & 44.55 \\
PM-HPMC & 20 & $17.99 \pm 2.037$ & 60.68 \\
PM-PEG & 20 & $16.70 \pm 0.200$ & 63.50 \\
PM-PVP & 20 & $18.81 \pm 1.114$ & 58.88 \\
KND-HPMC & 20 & $20.06 \pm 1.195$ & 56.15 \\
KND-PEG & 20 & $21.41 \pm 1.437$ & 53.20 \\
KND-PVP & 20 & $17.16 \pm 0.830$ & 62.49 \\
RE-HPMC & 20 & $26.53 \pm 1.425$ & 42.09 \\
RE-PEG & 20 & $28.20 \pm 0.762$ & 38.35 \\
RE-PVP & 20 & $22.26 \pm 2.306$ & 51.13 \\
\hline
\end{tabular}

\subsubsection{Cell Viability Assays}

Many compounds extracted from plants can modulate cell proliferation, acting as cytotoxic agents, as is the case for antineoplastic drugs. On the other hand, they can act by stimulating the cellular growth with potential application in the wound healing [34].

The ability of ABAM alone as well as PMs and SDs in interfering the cell viability is shown in Figure 7. The results show that no significant difference $(p<0.05)$ was found between ABAM dispersions and that of the control group, with a cell viability higher than $80 \%$, which classifies ABAM and its SDs as non-cytotoxic. Therefore, the results of the anti-inflammatory activity and the cell viability test indicate that a concentration of $20 \mu \mathrm{g} / \mathrm{mL}$ of ABAM (alone and as SDs) is effective and 
safe, respectively. In fact, the confirmation of low cytotoxic effect in addition to the anti-inflammatory activity is crucial during the investigation of novel compounds and new therapeutic systems as potential anti-inflammatory agents.

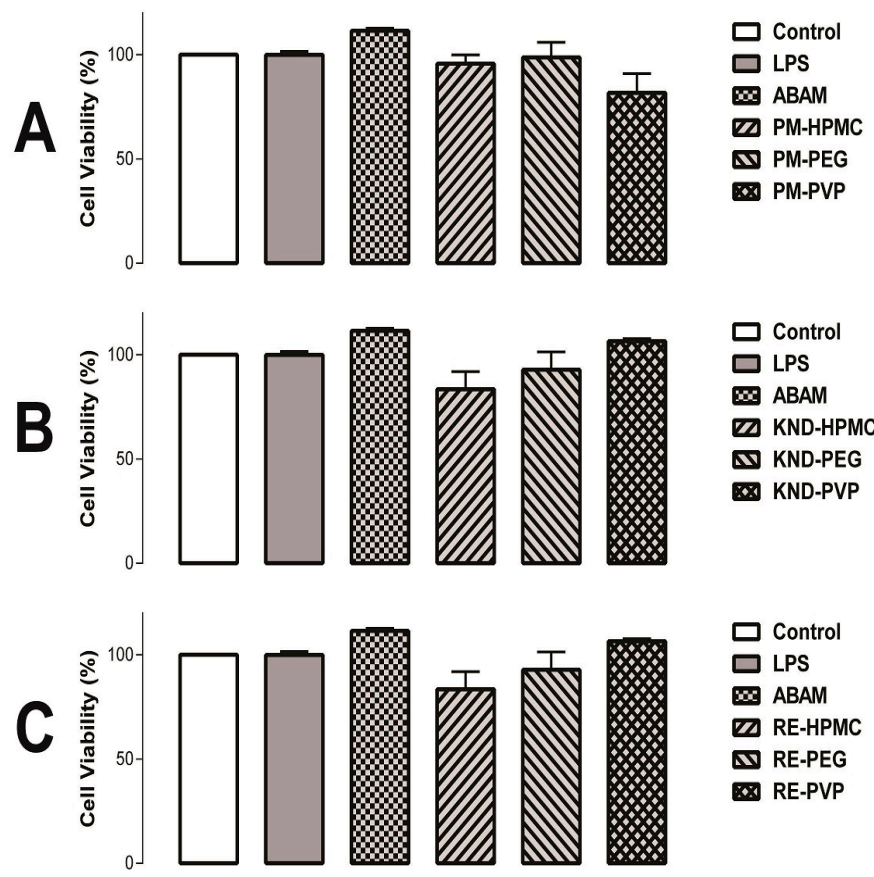

Figure 7. Effect of ABAM (alone and dispersed within the hydrophilic polymers) on cell viability. (A) Cell viability of the physical mixtures and ABAM compared to the control group; (B) Cell viability of ABAM and its SDs prepared by KND compared to that of the control group; (C) Cell viability of ABAM and its SDs prepared by RE compared to that of the control group. $p>0.05$ when compared with the control group by one-way ANOVA followed by Newman-Keuls test.

\section{Materials and Methods}

\subsection{Material}

ABAM was obtained from the commercial Protium oleoresins acquired in the Amazon state, AM, Brazil. PVP K30 and HPMC were purchased from Sigma Aldrich and PEG 6000 was obtained from Biotec Labmaster LTD (Pinhais, Paraná, Brazil ). The solvents used were all of analytical grade. All experiments were conducted using purified water $(<1.3 \mu \mathrm{S})$ obtained by a reverse osmosis system, model OS50LX, Gehaka (São Paulo, SP, Brazil). All reagents were of analytical grade.

\subsection{Preparation of $S D s$}

Solid dispersions were prepared by physical mixture (PM), kneading (KND) and rotary evaporation (RE) methods using the weight ratio of 1:1 (ABAM:hydrophilic polymer).

\subsubsection{SD Obtained by PM}

ABAM and the respective polymer (PVP K-30, PEG 6000 or HPMC) were precisely weighed following the 1:1 (w:w) ratio. Further, the mixtures were triturated/homogenized with mortar and pestle and stored in airtight glass desiccators under vacuum until use.

\subsubsection{SD Obtained by KND}

ABAM and each polymer were weighted (1:1) and triturated/homogenized with mortar and pestle followed by the addition of a mixture of acetone:water $(75: 25, v: v)$. The resulting solution was 
dried in an oven for fifteen hours at a temperature of $60{ }^{\circ} \mathrm{C}$ and then stored in a desiccator under vacuum for future analysis.

\subsubsection{SD Obtained by RE}

ABAM and each polymer were weighed separately $(1: 1, w: w)$ and dissolved in acetone:water $(75: 25, v: v)$ followed by evaporation under vacuum at $75^{\circ} \mathrm{C}$ using a rotary evaporator Model RV 10 (GEHAKA IKA ${ }^{\circledR}$, São Paulo, Brazil), operating at $150 \mathrm{rpm}$ for $15 \mathrm{~min}$. The resulting SD was kept in a desiccator for evaporation of the residual solvent.

\subsection{Physicochemical Characterization}

\subsubsection{Fourier Transform Infrared}

FTIR spectroscopic analysis was performed in an IR Prestige-21 equipment (Shimadzu Corporation, Kyoto, Japan), where the samples were prepared as $\mathrm{KBr}$ pellets using a hydraulic press at 10 tons of pressure. The analysis was carried out in the $4000-400 \mathrm{~cm}^{-1}$ region with 15 scans and spectral resolution of $4 \mathrm{~cm}^{-1}$.

\subsubsection{Scanning Electronic Microscopy}

The samples were mounted on aluminum stubs using double-sided adhesive tape. The morphological analysis was performed on a Hitachi TM-3000 Tabletop Microscope (Hitachi Ltd., Tokyo, Japan) at a magnification of 500×. The SEM images were obtained at an accelerating potential of $15 \mathrm{kV}$ under reduced pressure.

\subsubsection{Powder X-ray Diffraction}

Powder X-ray diffraction (PXRD) analysis were carried out using a Bruker D2 Phaser (Bruker Corporation, Billerica, MA, USA), with CuK $\alpha$ radiation $(\lambda=1.54 \AA$ ) at a voltage of $30 \mathrm{kV}$ and a current of $15 \mathrm{~mA}$ using a Lynxeye detector. Samples were scanned at room temperature over a period of $2 \mathrm{~h}$ at a range of $5-40^{\circ}$ at $0.05^{\circ} / \mathrm{s}$.

\subsubsection{Thermogravimetry}

TG thermograms were obtained using a TGA-50 Shimadzu ${ }^{\circledR}$ (Tokyo, Japan) in the temperature range of $30-600{ }^{\circ} \mathrm{C}$, using alumina crucibles with approximately $2 \mathrm{mg}$ of samples under dynamic nitrogen atmosphere $\left(50 \mathrm{~mL} \cdot \mathrm{min}^{-1}\right)$ and heating rate of $10^{\circ} \mathrm{C} \cdot \mathrm{min}^{-1}$. TG/DTG was calibrated using $\mathrm{CaC}_{2} \mathrm{O}_{4} \cdot \mathrm{H}_{2} \mathrm{O}$ according to ASTM standards.

\subsubsection{Differential Scanning Calorimetry}

DSC thermal analysis was carried out in a DSC-50 cell Shimadzu ${ }^{\circledR}$ (Tokyo, Japan) using approximately $2 \mathrm{mg}$ of sample in aluminum crucibles under dynamic nitrogen atmosphere $\left(50 \mathrm{~mL} \cdot \mathrm{min}^{-1}\right)$ and heating rate of $10{ }^{\circ} \mathrm{C} \cdot \mathrm{min}^{-1}$ at a temperature range of $30-500{ }^{\circ} \mathrm{C}$. The temperature and heat flow of the DSC instrument was calibrated with indium (melting point $=157.5^{\circ} \mathrm{C}$ and $\left.\Delta \mathrm{H}=26.7 \mathrm{~J} \cdot \mathrm{g}^{-1}\right)$.

\subsection{In Vitro Anti-Inflammatory Study}

In order to assess the production of nitric oxide (NO) by LPS-stimulated J774 macrophages, nitrite levels in culture medium was determined by Griess reaction. Cells were cultured in 24-well culture plates at a density of $1 \times 10^{6}$ cells $/ \mathrm{mL}$ and incubated at $37^{\circ} \mathrm{C}$ in a $5 \% \mathrm{CO}_{2}$ atmosphere for $2 \mathrm{~h}$ for the adhesion of macrophages. Cells were stimulated with $1 \mu \mathrm{g} / \mathrm{mL}$ of LPS for $60 \mathrm{~min}$. After stimulation, cells were obtained with ABAM alone and as solid dispersions at a concentration of 
$20 \mu \mathrm{g} / \mathrm{mL}$. The culture was again incubated at $37^{\circ} \mathrm{C}$ at a $5 \% \mathrm{CO}_{2}$ atmosphere for $24 \mathrm{~h}$, where the supernatant was then collected for quantification of NO.

\subsubsection{Quantification of Nitric Oxide (NO)}

Inhibition of nitric oxide production was determined by measuring nitrite levels in the supernatant of the LPS-stimulated J774 macrophage cells. NO, determined as the accumulation of nitrite $\left(\mathrm{NO}^{2-}\right)$ in the supernatant, was measured spectrophotometrically using Griess reagent [35-37]. In 96 well-plates, $50 \mu \mathrm{L}$ aliquots of cell supernatants were mixed with $100 \mu \mathrm{L}$ of Griess reagent (1:1 mixture of $1 \%$ sulfanilamide dihydrochloride and $N$-[1-naphthyl]-etilenodiamine $0.1 \%$ ), followed by incubation for $10 \mathrm{~min}$ at room temperature and protected from light. The absorbance at $570 \mathrm{~nm}$ was determined spectrophotometrically in a micro-plate reader (Beckman Coulter, Inc., Brea, CA, USA).

\subsubsection{Cell viability Assay}

The viability of cell growth was determined using the 3-(4,5-dimethylthiazol-2-yl)-2.5diphenyl-2H-tetrazolium bromide (MTT) assay. Briefly, for all experiments, $100 \mu \mathrm{L}$ of cells was seeded in 96-well plates $\left(3.4 \times 10^{3}\right.$ cells/well). After $24 \mathrm{~h}$, ABAM alone and as solid dispersions $(20 \mu \mathrm{g} / \mathrm{mL})$ was added to each well, where the cells were incubated for $24 \mathrm{~h}$. At the end of incubation time, the plates were centrifuged and the medium was replaced by fresh medium $(150 \mu \mathrm{L})$ containing MTT (Sigma, St. Louis, MO, USA, $0.5 \mathrm{mg} / \mathrm{mL}$ ). Four hours later, the formazan product was dissolved in $150 \mu \mathrm{L}$ DMSO and the absorbance was measured at $540 \mathrm{~nm}$ using a multiplate reader (DTX 880 Multimode Detector, Beckman Coulter Inc., Fullerton, CA, USA). Each individual measurement was performed in triplicate.

\subsection{Statistical Analysis}

Results are presented as mean \pm standard error. Two-way ANOVA with Newman-Keuls post-test was performed using GraphPad Prism version 5.00 (San Diego, CA, USA). $p$-Values less than 0.05 were considered statistically significant.

\section{Conclusions}

In this study, the physicochemical characterization indicated that ABAM was successfully prepared as amorphous solid dispersions with HPMC, PEG 6000 and PVP-K30. The decreased crystallinity of ABAM in the solid dispersions, as confirmed by XRD and DSC analysis, indicates the formation of eutectic mixtures, where the RE method seems to be the one that caused the most significant amorphization. ABAM and its SDs were shown to be safe as they did not cause a significant reduction in the viability of J774 macrophages after $24 \mathrm{~h}$ of treatment. Both ABAM alone and as SDs inhibited NO. production when compared to the LPS group, showing its anti-inflammatory potential. Further studies need to be carried out in order to investigate the influence of a reduction in ABAM's crystallinity on its aqueous solubility.

Acknowledgments: The authors want to acknowledge the Laboratório de Peneiras Moleculares (Universidade Federal do Rio Grande do Norte/Brazil) for the PXRD analysis and the Laboratório de Caracterização Estrutural de Materiais (Universidade Federal do Rio Grande do Norte/Brazil) for the SEM analysis.

Author Contributions: Walter Ferreira da Silva Júnior, Danielle Lima Bezerra de Menezes, Patrícia Danielle Oliveira de Almeida, Emerson Silva Lima performed the experimentes. Walter Ferreira da Silva Júnior, Valdir Florêncio da Veiga Júnior, Eduardo Pereira de Azevedo, Jonas Gabriel de Oliveira Pinheiro, Natan Emanuell de Sobral e Silva and Ádley Antonini Neves de Lima contributed with the development of concept, data analysis and writing the manuscript.

Conflicts of Interest: The authors declare no conflict of interest. 


\section{References}

1. Weeks, A.; Daly, D.C.; Simpson, B.B. The phylogenetic history and historical biogeography of the frankincense and myrrh family (Burseraceae) based on nuclear and chloroplast sequence data. Mol. Phylogenet. Evol. 2005, 35, 85-101. [CrossRef] [PubMed]

2. Lorenzi, H. Árvores Brasileiras: Manual de Identificação e Cultivo de Plantas Arbóreas Nativas do Brasil, 3rd ed.; Instituto Plantarum: Nova Odessa, Brazil, 2008.

3. Siani, A.C.; Ramos, M.F.S.; Menezes, O.; Ribeiro, R.; Fernandez, E.; Soares, R.O.; Rosas, E.C.; Susunaga, G.S.; Guimarães, A.C.; Zoghbi, M.G.; et al. Evaluation of antiinflamatory-related activity of essential oils from the leaves and resin of species of Protium. J. Ethnopharmacol. 1999, 66, 57-69. [CrossRef]

4. Rüdiger, A.L.; Veiga Junior, V.F. Chemodiversity of ursane- and oleanane-type triterpenes in Amazonian Burseraceae oleoresins. Chem. Biodivers. 2013, 10, 1142-1153. [CrossRef] [PubMed]

5. Veiga Junior, V.F.; Silva, J.R.A.; Zoghbi, M.G.B.; Patitucci, M.L.; Pinto, A.C. Utilização de cromatografia gasosa de alta resolução na detecção de classes de terpenos em extratos brutos vegetais. Quím. Nova 1995, 18, 262-266.

6. $\quad$ Bandeira, P.N.; Lemos, T.L.; Costa, S.M.; Santos, H.S. Obtenção de derivados da mistura triterpenoídica $\alpha$ e $\beta$-amirina. Rev. Bras. Farmacogn. 2007, 17, 204-212. [CrossRef]

7. Matos, I.; Bento, A.F.; Marcon, R.; Claudino, R.F.; Calixto, J.B. Preventive and therapeutic oral administration of the pentacyclic triterpene $\alpha, \beta$-amyrin ameliorates dextran sulfate sodium-induced colitis in mice: The relevance of cannabinoid system. Mol. Imunnol. 2013, 54, 482-492. [CrossRef] [PubMed]

8. Holanda, S.A.; Pinto, L.M.S.; Guedes, M.A.; Cunha, G.M.A.; Chaves, M.H.; Santos, F.A.; Rao, V.S. Antinoceptive effect of triterpenoid $\alpha, \beta$-amyrin in rats on orofacial pain induced by formalin and capsaicin. Phytomedcine 2008, 15, 630-634. [CrossRef] [PubMed]

9. Oliveira, F.A.; Vieira-Júnior, G.M.; Chaves, M.H.; Almeida, F.R.C.; Florêncio, M.G.; Lima-Junior, R.C.P.; Silva, R.M.; Santos, F.A.; Rao, V.S.N. Gastroprotective and anti-inflammatory effects of resin from Protium heptaphyllum in mice and rats. Pharmacol. Res. 2004, 49, 105-111. [CrossRef] [PubMed]

10. Oliveira, F.A.; Chaves, M.H.; Almeida, F.R.; Lima-Júnior, R.C.; Silva, R.M.; Maia, J.L.; Brito, G.A.; Santos, F.A.; Rao, V.S. Protective effect of $\alpha$ - and $\beta$-amyrin, a triterpene mixture from Protium heptaphyllum (Aubl.) March. trunk wood resin, against acetaminophen-induced liver injury in mice. J. Ethnopharmacol. 2005, 98, 103-108. [CrossRef] [PubMed]

11. Burton, L.; Ying, W.; Gandhi, R.; West, R.; Huang, C.; Zhou, S.; Shak, K.; Chen, J.; Shen, X. Development of a precipitation-resistant solution formulation to increase in vivo exposure of a poorly water-soluble compound. Int. J. Pharm. 2012, 433, 94-101. [CrossRef] [PubMed]

12. Mishra, B.; Sahoo, J.; Dixit, P.K. Formulation and process optimization of naproxen nanosuspensions stabilized by hydroxy propryl methyl cellulose. Carbohydr. Polym. 2015, 127, 300-308. [CrossRef] [PubMed]

13. Gulsun, T.; Gursoy, R.N.; Oner, L. Design and characterization of nanocrystal formulations containing ezetimibe. Chem. Pharm. Bull. 2011, 59, 41-45. [CrossRef] [PubMed]

14. Thadkala, K.; Nanam, P.K.; Rambabu, B.; Sailu, C.; Aukunuru, J. Preparation and characterization of amorphous ezetimibe nanosuspensions intended for enhancement of oral bioavailability. Int. J. Pharm. Investig. 2014, 4, 131-137. [PubMed]

15. Duarte, I.; Corvo, M.L.; Serôdio, P.; Vicente, J.; Pinto, J.F.; Temtem, M. Production of nano-solid dispersions using a novel solvente-controlled precipitation process-Benchmarking their in vivo performance with an amorphous micro-sized solid dispersion produced by spray drying. Eur. J. Pharm. Sci. 2016, 93, $203-214$. [CrossRef] [PubMed]

16. Mendes, C.; Buttchevitzs, A.; Kruger, J.H.; Kratz, J.M.; Simões, C.M.O.; Benedet, P.O.; Oliveira, P.R.; Silva, M.A.S. Inclusion complexes of hydrochlorothiazide and $\beta$-cyclidextrin: Physicochemical characteristics, in vitro and in vivo studies. Eur. J. Pharm. Sci. 2016, 83, 71-78. [CrossRef] [PubMed]

17. Alves, L.D.S.; de La Roca, M.F.S.; Albuquerque, C.T.; Silva, É.R.; Vieira, A.C.C.; Fontes, D.A.F.; Figueirêdo, C.B.M.; Soares-Sobrinho, J.L.; Rolim-Neto, P.J. Solid dispersion of efavirenz in PVP K-30 by conventional solvent and kneading methods. Carbohydr. Polym. 2014, 104, 166-174. [CrossRef] [PubMed]

18. Wang, B.; Wang, D.; Zhao, S.; Huang, X.; Jianbin, Z.; Yan, L.V.; Liu, X.; Guojun, L.V.; Xiaojun, M. Evaluate the ability of PVP to inhibit crystallization of amorphous solid dispersions by density functional theory and experimental verify. Eur. J Pharm. Sci. 2017, 96, 45-52. [CrossRef] [PubMed] 
19. Marsac, P.; Li, T.; Taylor, L. Estimation of drug-polymer miscibility and solubility in amorphous solid dispersions using experimentally determined interaction parameters. Pharm. Res. 2009, 26, 139-151. [CrossRef] [PubMed]

20. Meaurio, E.; Zuza, E.; Sarasua, J.R. Miscibility and specific interactions in blends of poly(L-lactide) with poly(vinylphenol). Macromolecules 2005, 38, 1207-1215. [CrossRef]

21. Park, Y.; Veytsman, B.; Coleman, M.; Painter, P. The miscibility of hydrogenbonded polymer blends: Two self-associating polymers. Macromolecules 2005, 38, 3703-3707. [CrossRef]

22. Li, B.; Wen, M.; Li, W.; He, M.; Yang, X.; Li, S. Preparation and characterization of baicalin-poly-vinylpyrrolidone coprecipitate. Int. J. Pharm. 2011, 408, 91-96. [CrossRef] [PubMed]

23. Singh, D.; Arya, P.V.; Sharma, A.; Dobhal, M.P.; Gupta, R.S. Modulatory potential of $\alpha$-amyrin against hepatic oxidative stress through antioxidant status in wistar albino rats. J. Ethnopharmcol. 2015, 161, 186-193. [CrossRef] [PubMed]

24. Abdel-Raouf, N.; Al-Enazi, N.M.; Al-Homaidan, A.A.; Ibraheem, I.B.M.; Al-Othman, M.R.; Hatamleh, A.A. Antibacterial $\beta$-amyrin isolated from Laurencia microcladia. Arab. J. Chem. 2015, 8, 32-37. [CrossRef]

25. Silverstein, R.M.; Webster, F.X.; Kiemle, D. Spectrometric Identification of Organic Compounds, 7th ed.; Wiley: New York, NY, USA, 2005.

26. Sharma, V.K.; Mazumdar, B. Feasibility and characterization of gummy exudates of Cochlospermum religiosum as pharmaceutical excipiente. Ind. Crop. Prod. 2013, 50, 776-786. [CrossRef]

27. Papadimitriou, S.A.; Barmpalexis, P.; Karavas, E.; Bikiaris, D.N. Optimizing the ability of PVP/PEG mixtures to be used as ppropriate carriers for the preparation of drug solid dispersions by melt mixing technique usingartificial neural networks: I. Eur. J. Pharm. Biopharm. 2012, 82, 175-186. [CrossRef] [PubMed]

28. Riekes, M.K.; Kuminek, G.; Rauber, G.S.; Campos, C.E.M.; Bortoluzzi, A.J.; Stulzer, H.K. HPMC as a potential enhancer of nimodipine biopharmaceutical properties via ball-milled solid dispersions. Carbohydr. Polym. 2015, 99, 474-482. [CrossRef] [PubMed]

29. Shi, C.; Tong, Q.; Fang, J.; Wang, C.; Wu, J.; Wang, W. Preparation, chacarterization and in vivo studies of amorphous solid dispersion of berberine with hydrogenated phosphatidylcoline. Eur. J. Pharm. Sci. 2015, 74, 11-17. [CrossRef] [PubMed]

30. Ramos, L.A.; Cavalheiro, T.G. Thermal behavior of loratadine. J. Therm. Anal. Calorim. 2007, 87, 831-834. [CrossRef]

31. Kumar, S.G.V.; Mishra, D.N. Preparation, characterization and in vitro dissolution studies of solid dispersion of meloxicam with PEG 6000. Yakugaku Zasshi 2006, 126, 657-664. [CrossRef]

32. Sethia, S.; Squillante, E. Solid dispersion of carbamazepine in PVP K30 by conventional solvent evaporation and supercritical methods. Int. J. Pharm. 2004, 272, 1-10. [CrossRef] [PubMed]

33. Shih, A.H.; Abdel-Wahab, O.; Patel, J.P.; Levine, R.L. The role of mutations in epigenetic regulators in myeloid malignancies. Nat. Rev. Cancer 2012, 12, 599-612. [CrossRef] [PubMed]

34. Biskup, C.S.; Sánchez, C.L.; Arrant, A.; Van Swearingen, A.E.; Kuhn, C.; Zepf, F.D. Effects of acute tryptophan depletion on brain serotonin function and concentrations of dopamine and norepinephrine in C57BL/6J and BALB/cJ mice. PLoS ONE. 2012, 7, e35916. [CrossRef] [PubMed]

35. Verma, N.; Tripathi, S.K.; Sahu, D.; Das, H.R.; Das, R.H. Evaluation of inhibitory activities of plant extracts on production of LPS-stimulated pro-inflammatory mediators in J774 murine macrophages. Mol. Cell. Biochem. 2010, 336, 127-135. [CrossRef] [PubMed]

36. Julião, L.S.; Piccinelli, A.L.; Marzocco, S.; Leitão, S.G.; Lotti, C.; Autore, G.; Rastrelli, L. Phenylethanoid glycosides from Lantana fucata with in vitro anti-inflammatory activity. J. Nat. Prod. 2009, 72, 1424-1428. [CrossRef] [PubMed]

37. Shrestha, S.S.; Amano, Y.; Narukawa, Y.; Takeda, T. Nitric oxide production inhibitory activity of flavonoids contained in trunk exudates of Dalbergia sissoo. J. Nat. Prod. 2008, 71, 98-101. [CrossRef] [PubMed]

Sample Availability: Samples of the compounds $\alpha, \beta$ amyrin. are available from the authors. 